\title{
DO AVANÇO DO PLANEJAMENTO, PROGRAMAÇÃO E CONTROLE DA PRODUÇÃO COMOATIVIDADES ESSENCIAIS DA EMPRESA À EDUCAÇÃO AMBIENTAL
}

\begin{abstract}
OLIVEIRA NETO, Geraldo Cardoso de
Post Graduate Studies Program in Administration. July Nine University (Uninove), Rua Francisco

Matarazzo, 612-ZIP Code 05001-100, São Paulo, Brazil. E-mail: geraldo.prod@ig.com.br

AZZOLINI JUNIOR, Walther

Post Graduate Studies Program in Industrial Engineering. Center University Araraquara (Uniara), Rua

Voluntários da Pátria, 1309 -ZIP Code 14801-320, São Paulo, Brazil. E-mail: wazzolini@uniara.com.br

BONILLA, Silvia $\mathrm{H}$.

Post Graduate Studies Program in Industrial Engineering. Paulista University (Unip), Rua Bacelar, 1212ZIP Code 04026-002, São Paulo, Brazil. E-mail: bonilla@unip.br
\end{abstract}

\begin{abstract}
ReSUMo
Neste artigo se aborda a evolução do Planejamento, Programação e Controle da Produção (PPCP) como atividades essenciais da empresa à educação ambiental, por meio da pesquisa exploratória em revisão bibliográfica. Neste cenário, apresentar-se-ão como objetivos gerais: i) uma nova forma de estruturar a produção, considerando a Produção Mais Limpa $(\mathrm{P}+\mathrm{L})$ no cerne das Instalações, Capacidade, Tecnologia e Terceirização da empresa, e ii) as mudanças de infraestrutura ao atendimento das necessidades delineadas pelo mercado consumidor e a disseminação da educação ambiental interna. As necessidades que surgem da nova forma se resumem em: adequação de instalações; implementação de tecnologias limpas na fabricação e manufatura e de ecorredes; instrução e disseminação de conceitos sobre educação ambiental internamente; simplificação dos fluxos produtivos; e necessidade de se adaptar aos paradigmas.
\end{abstract}

Palavras-chave: Produção Mais Limpa, Produção enxuta, Planejamento, Programação e Controle da Produção com Educação Ambiental.

\begin{abstract}
This work addresses the evolution of Planning, Programming and Control of Production (PPCP) as essential activities of the company towards the insertion of environmental education. The approach is based on an exploratory research and a critical bibliographic revision. Two main objectives were established: i) a new way of production organization, by considering cleaner production from company utilities to production capacity, technology and outsourcing and ii) infrastructure changes related to market attendance and environmental education dissemination. Needs that arise can be grouped as follows: utilities adequacy, cleaner technologies and ecochains implementation; instruction and dissemination of environmental education; and necessity of the adoption of new paradigms.
\end{abstract}

Keywords: Cleaner Production, Lean Production, Planning, Programming and Control with environmental education. 


\section{INTRODUÇão}

As estratégias competitivas de natureza tanto corporativa quanto de manufatura têm evoluído mais acentuadamente com a introdução do paradigma da Manufatura Enxuta, a partir da década de 70. Desde então, as organizações passaram a adotar critérios rigorosos de avaliação do mercado, o qual passou a ser regido pela oferta e não mais pela demanda. A competitividade entre as empresas tornou-se mais acirrada com a queda de barreiras comerciais a partir do fenômeno da globalização. Consequentemente, $o$ ocidente evoluiu para a compreensão desse novo paradigma como uma nova maneira de abordagem da manufatura, junto ao processo de gestão da organização e comos sistemas integrados por computador Material Requeriment Planning (MRP) e Enterprise Resources Planning (ERP).

Norman (1983) aponta que a essência do MRP é que se considera a demanda (o cliente) para determinar os materiais e outras exigências. À medida que a tecnologia de computação avançou, o potencial crescente de aplicação desse conceito de planejamento amplo foi ficando mais evidente, passando do MRP para o MRPII e, posteriormente, nos anos 90, para o ERP que configura a era dos sistemas gerenciais integrados. Diferença radical na maneira pela qual esses componentes são entregues ao cliente (WOMACK; JONES, 2004). A partir do contexto descrito na última década, a pesquisa aplicada ao estudo do processo de evolução dos sistemas de gestão da produção induziu pesquisadores $-\mathrm{e}$ isso no mundo todo - a estudar em detalhes uma questão que fez com que os autores deste artigo estudassem com objetivo geral os novos paradigmas que surgiram ao longo dos últimos dez anos nesse cenário. Esse trabalho foi feito considerando a evolução das técnicas auxiliares do PPCP tradicional ao novo conceito relacionado ao tema Planejamento, Programação e Controle da Produção e a Educação Ambiental (PPCPEA) por toda a indústria.

Como objetivos específicos que justificamo objetivo geral:

- conceituar a nova retórica do PPCP para o PPCPEA através da revisão bibliográfica;
- propor a estruturação da Produção Mais Limpa $(\mathrm{P}+\mathrm{L})$ no sistema produtivo, considerando as instalações, a capacidade, a tecnologia e a verticalização ou terceirização, a fim de reduzir a poluição;

- propor infraestrutura com pessoas educadas a práticas ambientais, com conhecimentos relativos à gestão ambiental, ao atual paradigma do sistema produtivo - Manufatura Limpa, a inserção do novo objetivo de desempenho da produção e a relação estreita entre PPCP enxuto e P+L;

- propor um modelo de PPCPEA flexível a discussões.

\section{Metodologia Da PESQuisa}

Esta pesquisa se caracteriza, quanto aos fins, como exploratória, uma vez que busca sistematizar conhecimento. Quanto aos meios, é uma pesquisa bibliográfica que contém uma análise crítica. Gil (2002) relata que a categoria da pesquisa exploratória desenvolve o levantamento bibliográfico.

A fim de alcançar os objetivos propostos em um primeiro momento, conceitua-se uma visão tradicional do PPCP frente às necessidades competitivas.

\section{Processo de Gestão da Produção \\ Evolução do PPCP ao PPCPEA}

O planejamento é uma formalização do que se pretende que aconteça em determinado momento no futuro (CORREAA; GIANESI; CAON, 2007). Esse planejamento tem como "fim que a produção ocorra eficazmente e produza produtos e serviços como deve" (SLACK; CAHMBERS; JOHNSTON, 2007). O controle pode ser definido, segundo apontam Peter e Certo (2005), de forma ordenada: primeiro estabelecem-se metas, depois é preciso compará-las com o realizado e por fim decidir-se por manter ou aplicar ações corretivas.

As empresas transformam produtos e serviços por meio do sistema produtivo, que conta com entradas (insumos) e saídas (produtos), planejados em termos de prazos (TUBINO, 2007). Os sistemas produtivos precisam de um plano de produção, cuja função é com base na previsão de vendas e na capacidade de 
produção para atender aos clientes. Corrêa e outros (2007) reforçam a importância estratégica do sistema de gestão da produção para o cumprimento dos objetivos organizacionais, inclusive para apoiar a tomada de decisões logísticas, que visa: planejar as necessidades futuras de capacidade produtiva; planejar os materiais comprados; planejar os níveis adequados de estoque; programar atividades de produção para garantir que os recursos produtivos envolvidos estejam sendo utilizados, em cada momento, nas coisas certas e prioritárias; ser capaz de saber e de informar corretamente a respeito da situação corrente dos recursos (pessoas, equipamentos, instalações, materiais) e das ordens (de compra e produção); ser capaz de prometer os menores prazos possíveis aos clientes e depois fazer cumpri-los e ser capaz de reagir eficazmente a crises de mercado. A evolução do PCP para o PPCP envolve uma série de decisões com o objetivo de definir o que, quanto e quando produzir e comprar, além dos recursos a serem utilizados de acordo (CORRÊA; GIANESI; CAON, 2007).

A partir da identificação desse processo de evolução, um elemento fundamental é entender o sistema de produção, isto é, como o fluxo de produção atinge determinados objetivos.

O sistema de produção deve responder à demanda de diferentes formas, com diferentes lead-time de fornecimento, sendo que algumas empresas produzem para o estoque, outras montam sob encomenda, outras fabricam sob encomenda e algumas desenvolvem projetos sob encomenda. Independentemente da maneira como a empresa programa o fluxo de materiais, o PPCP representa uma importância considerável na vantagem competitiva da organização, que precisa estar atenta à necessidade dos clientes.

Sacomano (2007) relata que o processo decisório ganhou novas dimensões nas organizações empresariais. A responsividade, a agilidade, a customização de produtos, acompanhadas de um mercado cada vez mais sensível aos aspectos de custo, qualidade, prazo, e flexibilidade, obriga a uma nova postura frente ao processo decisório, que também deve ser muito mais ágil e responsivo do que na fase anterior definida apenas

\section{como PPCP.}

Uma sensibilidade do mercado atual é a propensão à compra de produtos e serviços que sejam ambientalmente corretos. Segundo Contador (2008), as empresas disputam vantagens competitivas no campo de competição relacionada à imagem da empresa.

Portanto, na atualidade, é de suma importância o produto ser projetado com responsabilidade ambiental; dessa forma, o PPCP programa o fluxo da produção preocupado inclusive como destino correto atribuído aos resíduos e às tecnologias limpas a serem utilizadas. $\mathrm{O}$ destino correto é incentivar a reciclagem e a reutilização dos resíduos no processo produtivo.

Percebe-se nitidamente que o novo direcionador de mercado está relacionado à empresa ambientalmente correta. Hoek e Erasmus (2000) corroborame afirmam que a filosofia "Lean and Green" tem como objetivo reduzir os impactos ambientais e melhorar o market share da empresa no mercado. Desse modo, para conseguir a vantagem competitiva planejada, as empresas precisam disputar no campo da imagem, e uma arma poderosa é proporcionar uma evolução do PPCP para o PPCPEA. Yuksel (2007) aponta que é necessário considerar as questões ambientais no Planejamento e Controle da Produção de maneira flexível e adaptativa ao sistema produtivo. Para isso, avalia-se a programação da produção, levantam-se os problemas ambientais e processam-se mudanças na programação.

\section{Relação entre Planejamento e Controle da Produção Enxuta e Produção Mais Limpa}

O planejador da produção deve decidir com racionalidade o controle dos recursos de manufatura escassos. Em 2001, a Asian Productivity Organization (2001) afirmou que as práticas e princípios da Manufatura Enxuta contribuem para a redução da poluição.

O consumo consciente atribui vantagens ao conceito de Produção Enxuta. As vantagens e conceitualização da Produção Enxuta, conforme Womack e Jones (2004), apresentam-se pela maneira de utilizar menores quantidades de recursos, isto é, reduzir desperdícios. No cotidiano, o planejador de produção precisa eliminar 
ou diminuir sete formas de desperdícios: 1) A produção além das necessidades, 2) Os defeitos e retrabalhos, 3) $\mathrm{O}$ inventário em excesso, 4) $\mathrm{O}$ processamento desnecessário, 5) A movimentação desnecessária de pessoas e materiais, 6) O transporte desnecessário de materiais e 7) Esperas desnecessárias de pessoas.

Assim é possível perceber que os conceitos de Manufatura Enxuta e de Produção Mais Limpa são alinhados, embora não tenham sido definidos com os mesmos propósitos. AManufatura Enxuta nasceu na indústria automobilística em 1950, com o firme propósito de gerar produtividade, a fim de permitir produzir cada vez mais com menos recursos. Assim, alinha-se aos propósitos da Produção Mais Limpa no âmbito de utilizar racionalmente os recursos, termo definido por Giannetti e Almeida (2006) como ecoeficiência.

Para essa finalidade se busca implementar a Produção Mais Limpa, com o objetivo de usar tecnologias mais limpas, comreciclagem de materiais, no descarte devido, no racionamento de água e energia, ou até mesmo na forma do PPCPEA estabelecer o plano estratégico, a fim de: 1) Mapear e entender os processos para eliminar desperdícios, 2) Equilibrar a produção entre a oferta e a demanda, evitando desperdícios, 3) Processar os produtos de forma enxuta, com isso é possível reduzir horas extras, consumo de energia e o uso indevido de matéria-prima, 4) Preservar a segurança e integridade de seus colaboradores, além de treiná-los a práticas ambientais e se tornarem multiplicadores na empresa e sociedade.

Surge, então, um "PPCP Lean and Green": ao mesmo tempo em que reduz a poluição, reduz tempos, desperdícios, custos, etc. Segundo US EPA(2000), a maior proposta do "Lean and Green" é rever os processos a fim de reduzir os tempos, os custos, racionalizar o uso de matéria-prima através da reciclagem ou do reuso. Outra característica importante é planejar produtos ambientais e analisar o ciclo de vida. Também se busca otimizar e unitizar o transporte, a fim de reduzir a emissão de $\mathrm{CO}^{2}$ e outros gases.

Portanto, o profissional que atua no PPCP precisa aderir à implementação da Produção Mais Limpa, principalmente pela estreita ligação com a Manufatura
Enxuta. Neste trabalho, apresentar-se-á o modelo de PPCPEA flexível a discussões, que integra os aspectos estruturais e infraestruturais.

\section{Proposta de estruturação da produção com práticas ambientais}

Azzolini Jr. (2004) relata que, para a estruturação da produção frente a uma nova estratégia competitiva, deve-se levar em conta as decisões que envolvem aspectos de estrutura. Os aspectos estruturais são: 1) instalações industriais, 2) capacidade produtiva, 3) estratégia de processo, 4) tecnologia, 5) verticalização ou terceirização e 6) planejamento e desenvolvimento de produtos. Os autores acrescentam a nova forma de estruturar a produção por meio da implementação da Produção Mais Limpa intrínseca aos aspectos estruturais corroborados por Azzollini Jr. (2004), a fim de reduzir a poluição de maneira consciente e contribuir com a estratégia competitiva empresarial. Propõe-se para vantagem competitiva umnovo objetivo de desempenho, considerando as práticas de sustentabilidade nas decisões, além de contribuir com os princípios da Manufatura Enxuta.

As organizações precisam se atentar às formas de organizar o trabalho, a fim de reduzir o uso de recursos e diminuir a poluição, de modo que o empresariado dissemine as práticas de $\mathrm{P}+\mathrm{L}$ para todas as pessoas envolvidas na cadeia de fornecimento, desde o fornecedor até o cliente.

Segundo Giannetti e Almeida (2006), a P+L visa melhorar a eficiência, a lucratividade e a competitividade das empresas, enquanto protege o ambiente, o consumidor e o trabalhador. É um conceito de melhoria contínua que tem por consequência tornar o processo produtivo cada vez menos agressivo ao homem e ao meio ambiente.

De acordo com o Senai (2003) as vantagens ambientais da $\mathrm{P}+\mathrm{L}$ são as de evitar a poluição antes que ela seja gerada, isto é, com consciência e entendimento sobre o impacto no meio ambiente, principalmente na eliminação de resíduos, no controle da poluição, no uso racional de energia, na melhoria da saúde e segurança do trabalho, com produtos e embalagens 
ambientalmente adequados. Já no planejamento do produto, as embalagens dos produtos devem ser eliminadas ou minimizadas. As vantagens econômicas da P+L são aparentes em longo prazo, pois no início do projeto é investido capital na adoção de novas tecnologias e modificações de processos existentes. Essas vantagens incluem aumento na eficiência do processo, gerando redução permanente de custos totais através do uso eficiente de matérias-primas, água e energia, e da redução de resíduos e emissões gerados, além de boas práticas operacionais.

Dessa maneira, as organizações passam a considerar aspectos sobre a sustentabilidade intrínsecos aos objetivos de desempenho. Conforme Slack e outros (2007), "os objetivos mais amplos que as operações produtivas necessitam perseguir para satisfazer a seus stakeholders formamum pano de fundo para todo o processo decisório da produção [...] no nível operacional é necessário um conjunto de objetivos mais estritamente definidos".

Os objetivos de desempenho, segundo Slack e outros (2007), são: qualidade, rapidez, confiabilidade, flexibilidade e custo. Os autores, na nova forma de estruturar a produção, consideram a $\mathrm{P}+\mathrm{L}$ como outro objetivo de desempenho. AP+L visa racionalizar o uso de recursos da natureza, buscando reciclar o máximo possível, e essa atitude consciente reflete na imagem de empresa confiável, segundo Contador (2008), frente à competitividade.

Frente à estruturação da $\mathrm{P}+\mathrm{L}$ no sistema produtivo, torna-se necessário 1) projetar as instalações para o atendimento às necessidades dos clientes, que incluem: arranjo físico fabril de máquinas, equipamentos, quantidade de pessoal de produção, redes de operações e localização geográfica. A nova estruturação da produção objetiva e a revisão dos elementos citados, incluindo as práticas reais de $\mathrm{P}+\mathrm{L}$ para uma tomada de decisão que vai além da busca de resultados financeiros, preocupa-se inclusive com as vantagens ambientais na interação da empresa com o meio ambiente.

Segundo Slack e outros (2007), o arranjo físico envolve: instalações, máquinas, equipamentos, pessoal da produção e projetos de redes de operações. Esses determinam a maneira pela qual os recursos são transformados - materiais, informação e clientes-e fluem através da operação. É importante frisar a implementação nas instalações fabris, máquinas e equipamentos, de tecnologias limpas, "sendo melhores e adequadas porque permitem utilizar totalmente os insumos, sem a geração de resíduos" (GIANNETTI; ALMEIDA, 2006).

Gaither e Frazier (2002) complementam, relatando sobre a localização no campo geográfico. Alocalização geográfica da empresa deve ser um local estratégico, que evite desperdício de tempo e combustível, próximo às rodovias, a fim de aumentar a responsividade e reduzir o nível de $\mathrm{CO}^{2}$ na atmosfera.

Para uma nova estruturação da produção, é importante salientar que uma produção sem comprometimento ambiental refletirá em um consumo alto de energia, gastos maiores com matéria-prima e horas extras, causando impactos irreversíveis ao meio ambiente, por utilizar os recursos de maneira indevida e excessiva. 2) Capacidade de produção-os conceitos tradicionais mencionam que a produção precisa utilizar o "máximo da capacidade de produção conseguido em condições normais de operação e por um determinado período de tempo" (LEWIS; SLACK, 2003). Gaither e Frazier (2002) complementam que a capacidade de produção deve ser estimada e perfeitamente planejada devido ao grau elevado de incerteza. As principais incertezas são geralmente ligadas às instalações e tecnologia: ausências e férias de empregados, quebras de máquinas e atrasos de entrega e, principalmente, a diferença de cadência entre produtos e serviços. Corrêa e outros (2007) corroboram e afirmam que planejar a capacidade é uma atividade crítica, desenvolvida paralelamente ao planejamento de materiais e com o uso do MRP II. Recentemente, Krajewski (2009) apontou que a tecnologia MRP sofreu algumas alterações para se adaptar à preocupação dos consumidores, empresários e governo com a degradação do meio ambiente, a fim de rastrear os resíduos e planejar o descarte adequado. O mundo capitalista busca sempre aumentos da lucratividade por meio de aumento da capacidade de produção. O incremento sugerido é focar além dos ganhos econômicos, visar tambémàs vantagens 
ambientais sob a ótica do desenvolvimento sustentável.

Sunkel (2001) alega que o Desenvolvimento Sustentável(DS) é um tema que as classes dirigentes da nossa região não poderão adiar, sob pena de sofrer graves conflitos internos e sérias dificuldades internacionais. Veiga (2005) reforça que, na atualidade, o DS constitui um dos principais resultados da disputa política pela definição, que apresenta umclaro predomínio da economia na determinação. Amazonas (2002) complementa que é mais do que isso: é a corrente principal da teoria econômica, a economia neoclássica em sua vertente ambiental, a teoria hegemônica na determinação do que seja o DS e, por consequência, do que seja a própria posição do meio ambiente na prática política, social e econômica. Portanto, propõese que a empresa precisa crescer economicamente, mas com educação ambiental. Para que isso ocorra, é imprescindível estabelecer a 3) estratégia de processo, visando tornar o sistema produtivo limpo.

"Processo produtivo é uma sequência de atividades organizadas que transformam as entradas dos fornecedores em saídas para os clientes, com valor agregado gerado pela unidade" (ROTONDARO,
2004). A "Produção Mais Limpa é a aplicação contínua de uma estratégia integrada de preservação ambiental e processos, produtos e serviços, para aumentar a eficiência de produção e reduzir riscos para o ser humano e o ambiente, intrínsecos ao sistema produtivo" (GIANNETTI; ALMEIDA, 2006). Portanto, o PPCP precisa evoluir e implementar a $\mathrm{P}+\mathrm{L}$ no processo produtivo e também utilizar 4) tecnologias limpas. Gaither e Fraizer (2002) relatam que a tecnologia é muito importante para a vantagem competitiva da empresa. Porém, na nova estrutura da produção, a tecnologia precisa ser limpa. Giannetti e Almeida (2006) apontam que tecnologia limpa é um processo aplicado à fabricação e manufatura que reduz a produção de efluentes ou outros resíduos, maximiza a qualidade do produto, bem como minimiza o uso de matéria-primae energia. Thrane e outros (2009) reforçam que o maior objetivo da implementação de tecnologias limpas é a melhora incremental no processo produtivo que traga redução ou eliminação da poluição.

Segundo Gaither e Fraizer (2002), os tipos de automação apresentam recursos diversos e são classificados conforme o Quadro 1.

\begin{tabular}{|c|c|c|}
\hline $\begin{array}{c}\text { Tipos de } \\
\text { máquinas }\end{array}$ & Descrição & Exemplos \\
\hline $\begin{array}{l}\text { Anexos de } \\
\text { máquina }\end{array}$ & $\begin{array}{l}\text { Máquinas que substituem o esforço humano por esforço de } \\
\text { máquina, e tipicamente executam de algumas a muitas } \\
\text { operações. Despejam cargas de produtos }\end{array}$ & $\begin{array}{l}\text { Anexos para avanço de magazine, dispositivos para centralização } \\
\text { e fixação rápidas para tornos, alimentadores em tiras para } \\
\text { máquinas de estampar, tremonhas vibratórias com balanças de } \\
\text { químicos em contêineres receptores. }\end{array}$ \\
\hline $\begin{array}{l}\text { Máquinas de } \\
\text { controle } \\
\text { numérico }(\mathrm{NC})\end{array}$ & $\begin{array}{l}\text { Máquinas com sistemas de controle que leem instruções e as } \\
\text { convertem para operações de máquina. }\end{array}$ & $\begin{array}{l}\text { Tornos, tornos mecânicos verticais, máquinas de fabricação de } \\
\text { pneus, máquinas de cura, máquinas de tecelagem. }\end{array}$ \\
\hline Robôs & $\begin{array}{l}\text { Manipuladores de uso geral reprogramáveis, de múltiplas fun- } \\
\text { ções, que possuem algumas características semelhantes às } \\
\text { humanas. }\end{array}$ & $\begin{array}{l}\text { Máquinas que soldam, pintam, montam, inspecionam a } \\
\text { qualidade, pegam, transportam e armazenam. }\end{array}$ \\
\hline $\begin{array}{l}\text { Inspeção } \\
\text { automatizada do } \\
\text { controle da } \\
\text { qualidade } \\
\end{array}$ & $\begin{array}{l}\text { Máquinas automatizadas que executam parte ou todo o } \\
\text { processo de inspeção. }\end{array}$ & $\begin{array}{l}\text { Verificações de circuitos eletrônicos, verificações de funções } \\
\text { ativadas por computador, robôs de pesagem, sistemas de inspeção } \\
\text { flexível. }\end{array}$ \\
\hline $\begin{array}{c}\text { Sistemas } \\
\text { automáticos de } \\
\text { identificação } \\
\text { (AIS) }\end{array}$ & $\begin{array}{l}\text { Tecnologias usadas em aquisição automática de dados de } \\
\text { produtos para entrada num computador. }\end{array}$ & $\begin{array}{l}\text { Sistemas de código de barras, contabilidade de estoques, entrada } \\
\text { de dados para controle de chão de fábrica, sistemas para ajustar } \\
\text { configurações de máquinas de produção. }\end{array}$ \\
\hline $\begin{array}{c}\text { Controles } \\
\text { automatizados } \\
\text { de processo }\end{array}$ & $\begin{array}{l}\text { Sistemas de computador que recebem dados sobre o processo } \\
\text { de produção e enviam ajustes para as configurações do } \\
\text { processo. }\end{array}$ & $\begin{array}{l}\text { Sistemas de controle para laminadores - na manufatura de pneus, } \\
\text { calandras no processamento de filme plástico, unidades de } \\
\text { destilação fracionada (craqueamento) em refinarias de petróleo. }\end{array}$ \\
\hline $\begin{array}{c}\text { Tecnologias Mais } \\
\text { Limpas } \\
\text { combinadas aos } \\
\text { tipos de } \\
\text { máquinas citadas }\end{array}$ & $\begin{array}{l}\text { Máquinas de anexo numérico, de controle numérico, de robôs, } \\
\text { de controle da qualidade ambiental, de sistemas automáticos de } \\
\text { identificação, de controles automatizados do processo, que } \\
\text { reduzem o descarte de efluentes ou outros resíduos e maximiza } \\
\text { a qualidade do produto, bem como o uso de matéria prima e } \\
\text { energia. }\end{array}$ & $\begin{array}{l}\text { Reciclagem de borracha, que entra } 90 \% \text { como carga de } \\
\text { enchimento no processo produtivo. }\end{array}$ \\
\hline
\end{tabular}

Quadro 1 - Tipos de automação. Fonte: Gaither e Fraizer, 2002 (adaptado pelos autores). 
Portanto, é imprescindível a implementação de Tecnologias Limpas no fluxo produtivo, na automação da montagem, nas manufaturas e nos sistemas de armazenamento e recuperação.

$\mathrm{Na}$ estruturação da produção, quase sempre "as empresas focam em suas competências essenciais e terceirizam as atividades de apoio, que geralmente fazem parte da logística operacional" (OLIVEIRA NETO, 2008). Houaiss (2008) menciona em seu dicionário que a 5) terceirização significa a "contratação de terceiros por parte de uma empresa, para realização de atividades gerenciais não essenciais". Na nova estruturação da produção é fundamental homologar os fornecedores certificados pela ISO 14001:2000. Mas, independentemente de se optar pela terceirização, a empresa precisa se estruturar em ecorredes. A analogia com os ecossistemas permite um passo além: fechar os ciclos de materiais e energia com a formação de uma ecorrede (Figura 1), que "imita" os ciclos biológicos fechados. A ecologia industrial propõe, portanto, fechar os ciclos, considerando que o sistema industrial não apenas interage com o ambiente, mas é parte dele e dele depende (GIANNETTI; ALMEIDA, 2006). $\mathrm{Na}$ atualidade, segundo Hall (2000) Walton e outros (1998), Bowen e outros (2001) e Sarkis (2003), há um grande e importante crescimento na função de suprimentos e fornecimentos em redes com o objetivo de reduzir a poluição ambiental. Esse conceito se denomina "Lean and Green Supply Chain".

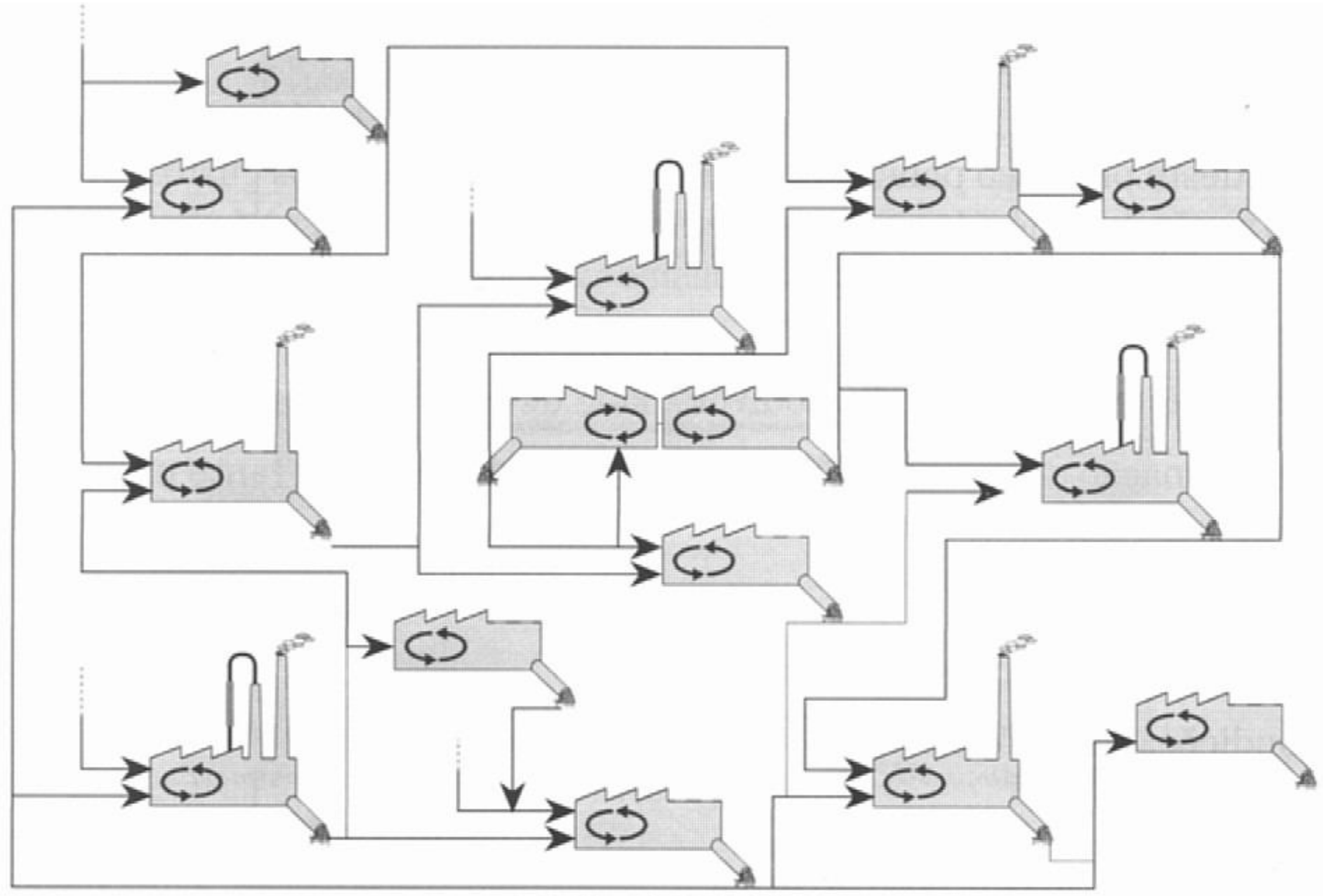

MEIO AMBIENTE

Figura 1 - Representação de uma ecorrede.

Fonte e figura original autorizada: Giannetti e Almeida 2006. 
Giannetti e Almeida (2006) relatam que o desenvolvimento dessa abordagem pretende oferecer um quadro conceitual para interpretar e adaptar a compreensão do sistema natural, e aplicar essa compreensão aos sistemas industriais com o objetivo de transformar o caráter linear do sistema industrial em um sistema cíclico, no qual matérias-primas, energia e resíduos sejam sempre reutilizados. Também se torna necessário, para uma nova estruturação da produção, a implementação de 6) Planejamento e desenvolvimento de produtos "ambientais corretos". Segundo Gaither e Frazier (2002), é importante planejar o produto, porque suas características afetam diretamente a maneira pela qual pode ser produzido e consequentemente determina o design do sistema de produção. Adicionalmente o projeto do produto afeta diretamente a sua qualidade, os custos de produção, os desperdícios com matériaprima e a satisfação do cliente. O planejamento de produtos é, portanto, crucial para o sucesso na competição global.

Na nova forma de estruturar a produção, é necessário estabelecer critérios ambientais no desenvolvimento de produtos. A NBR ISO 14001:2000 relata que as organizações precisam formar grupos a fim de avaliar todos os produtos, componentes ou matérias-primas utilizados, a fim de selecionar categorias de produtos para identificar os de menor impacto ambiental. Furtado (2005) menciona que o engenheiro de produção precisa ser compromissado com a preservação do meio ambiente através da utilização de materiais renováveis que tenham baixo impacto socioambiental, objetivando redução do uso de energia por unidade de bens e serviços, e redução do consumo de materiais através de reciclagem, reuso e remanufatura.

Além disso, o design do produto precisa considerar o eco-design, segundo (ZHU; SARKIS; CORDEIRO, 2006) (TSOULFAS; PAPPIS, 2008), que se inicia desde a concepção e projetação, manufatura e processos de suporte, com confiabilidade, sustentabilidade e competitividade.
Essa estratégia tem por objetivo fechar os ciclos, visando à prevenção (ideal) ou a minimização da geração de resíduos - especialmente os perigosos e à redução do uso de água.

Outra característica importante, conforme Shin e outros (2008) e Yuksel (2007), é a inovação incremental na composição de produtos, que visa à utilização de componentes recicláveis. Para isso é feito um estudo do tempo de vida útil dos componentes ou produtos e seus reflexos na decomposição no solo; o objetivo principalé substituir os materiais mais poluentes por recursos renováveis.

\section{Proposta de infraestrutura com práticas ambientais}

Entende-se por infraestrutura o conjunto de elementos estruturais que enquadrame suportam toda uma estrutura, possui concepções diferenciadas em diversas áreas do conhecimento, conforme Azzolini Jr. (2004). Sendo assim, para a concepção de práticas ambientais por toda a estrutura empresarial, torna-se necessário: 1) Implementar estratégia de recursos humanos, a fim de disseminar educação ambiental. Segundo Andrade e outros (2000), internamente, a organização deve conduzir programas de educação ambiental para instruir e disseminar conceitos sobre economia ambiental, ecologia geral e aplicada, meio ambiente e qualidade de vida, avaliação dos impactos ambientais, desenvolvimento sustentável, legislação ambiental, empreendimentos ecológicos e auditoria e certificação ambiental, a fim de "reduzir a quantidade de reagentes tóxicos que são descartados no ambiente, e fazer com que materiais, como a água e matéria-prima, circulem o máximo possível dentro do processo antes do descarte de forma tratada" (GIANNETTI; ALMEIDA, 2006).

A implementação da estratégia no gerenciamento de pessoal, para a conscientização dos colaboradores sobre os aspectos ambientais na produção, é o momento de colocar em prática a metodologia proposta, "formando Eco Times" (NEVENS; DESSEIN; MEUL; ROGGE; VERBRUGGEN, MULIER, PASSEL, LEPOUTRE; 
HONGENAERT, 2008).

Mas antes é preciso assimilar que implementar uma estratégia não é uma tarefa fácil: é preciso verificar o impacto sobre a mudança. Dessa forma, Wright e Parnell (2000) relatam a necessidade de estruturar a liderança, o poder e a cultura organizacional, a fim de possibilitar que os funcionários trabalhem juntos na implementação da gestão ambiental. Barbieri (2007) assevera que a educação ambiental deve estimular as pessoas a serem portadoras de soluções e não apenas de denúncias, embora estas devam ser as primeiras atitudes diante dos desmandos socioambientais. Deve também produzir mudanças nas suas próprias condutas, modificando, por exemplo, seus hábitos de consumo.

2) Inserir na gestão da qualidade da empresa a gestão ambiental, objetivando implementar a ISO 14000 nos processos organizacionais. Barbieri e Cajazeira (2009) mencionam que a evolução da gestão ambiental empresarial, alinhada à estratégia da empresa, seguiu caminho similar ao da qualidade. A pressão exercida pelas legislações ambientais para tornar as leis mais rigorosas e sua fiscalização mais efetiva fez com que as empresas passassem a controlar a poluição, mas não foi somente por pressões externas que essa área caminhou. Muitas empresas, entidades e instituições de ensino estão formulando propostas de gestão ambiental coerentes com os objetivos do desenvolvimento sustentável, criando para isso modelos de gestão. A normalização ISO 14000, segundo Carvalho e Paladini (2005), tem por objetivo equilibrar a proteção ambiental e a prevenção da poluição com as necessidades socioeconômicas da população. Segundo a NBR ISO 14001:2000 (2003), meio ambiente é conceituado como: a circunvizinhança em que a organização opera, incluindo ar, água, solo, recursos naturais, flora, fauna, seres humanos e suas inter-relações. É, portanto, imprescindível que a organização se preocupe com os aspectos e impactos ambientais de qualquer modificação do meio ambiente, tendo como responsabilidade o comprometimento da alta gerência e todos os empregados, promover treinamentos, conscientização, competências com uma comunicação ao pessoal envolvido, e assegurar o fornecimento de um nível apropriado de recursos para garantir a implementação e manutenção do sistema de gestão ambiental.

3) Estabelecer no plano estratégico da empresa a estreita relação entre PPCP enxuto e a $P+L$ com o objetivo de implementar a nova concepção de (PPCPEA) no sistema de produção. Nas últimas décadas, houve a ruptura do modelo de produção, de empurrada para puxada, de Fim de Tudo para $\mathrm{P}+\mathrm{L}$. Na atualidade, além de as empresas, por meio do PPCP visarem características de empresas enxutas, também visam planejar, através do MRP, o descarte de resíduos de maneira correta, ou até mesmo assimilar o subproduto no fluxo produtivo, a fim de adquirir vantagens ambientais e econômicas. Nielsen e Muller (2009) asseveram a necessidade de simplificar os fluxos produtivos com a finalidade de economia de materiais. Dessa forma, dois sistemas da administração da produção são imprescindíveis: Just in Time (JIT) e MRP. Taylor (2005) aponta que é imperativo que a empresa trabalhe no sistema de administração da produção em regime de JIT para que os fornecedores possam transformar grandes embarques de materiais em lotes que são enviados para centrais de recebimentos em embarques no tempo certo diretamente à fábrica, eliminando os estoques excessivos.

Conforme Nielsen e Muller (2009), Allen e outros (1999) e Tainter e outros (2003), a evolução do sistema natural e social intrínseco ao sistema produtivo enxuto faz com que as empresas utilizem novas formas de organizar o trabalho e se adaptem ao processo produtivo, principalmente no suprimento e fornecimento. Vais e outros (2006) corroboram e afirmam que "a essência da filosofia enxuta objetiva na identificação e eliminação de desperdícios em materiais, transporte, inventário, na movimentação, no tempo de espera, nos retrabalhos e defeitos na produção, em síntese, busca fazer mais com menos 
- menos recursos, menos esforço, menos equipamentos, menos tempo". O foco do "Lean and Green", além desses já citados, busca reduzir o consumo de energia e de água.

Segundo Corrêa e outros (2007), a introdução do sistema na administração da produção MRP contribui para simplificar a gestão dos materiais, sejam comprados ou fabricados. A extensão para o MRP II complementa sua utilidade, levando em consideração a capacidade suficiente para realizar o plano de produção e também os recursos humanos e equipamentos suficientes para cumprir o plano no prazo.

Recentemente, Krajewski (2009) aponta que a tecnologia MRP na elaboração do master planning system (MPS) pode gerar relatórios que estabeleçam a quantidade de resíduos esperada durante o processo de produção e quando ocorrerá. Dessa forma as empresas podem, em alguns casos, identificar seus problemas de resíduos antes de eliminá-los e, em outros, planejar o descarte adequado, além de gerar uma documentação formal a respeito do controle das emissões.

4) Disseminar a conscientização ambiental na empresa, a fim de envolver a estrutura, objetivando a aceitação à evolução paradigmática do sistema produtivo para uma manufatura limpa. Para isso, apresentar-se-ão os Paradigmas Estratégicos da Gestão da Manufatura (Pegem) e o atual, necessários para estruturar a produção, denominada pelos autores de Manufatura Limpa. Na concepção deste artigo, paradigma significa a "estrutura das revoluções científicas" (Kuhn, 1962). Godinho (2004) faz um amplo estudo da relação da escolha dos sistemas de controle (JIT e MRP. etc.) relacionados ao paradigma, no qual a manufatura está inserida, e conclui que cada paradigma produtivo citado guarda relação com o processo de fabricação, e sua identificação no cenário competitivo é altamente necessária para que o sistema não apresente as costumeiras restrições encontradas nas empresas. O Quadro 2 mostra a evolução dos Pegem que direcionam a estratégia competitiva. Percebe-se que, com o passar dos anos, sempre surgem novos desafios, que incentivam as empresas a mudar a forma de organizar seus negócios e, principalmente, a se adaptar constantemente para permanecer no mercado.

$\mathrm{Na}$ atualidade as empresas buscam novos métodos, a fim de reduzir a poluição, preocupam-se com as gerações futuras e também visam se manter competitivas frente ao novo direcionador de mercado "a imagem de empresa ambientalmente correta" e com isso tendem a comprar produtos e serviços ambientalmente corretos. Dessa forma as indústrias de transformação estão se adaptando ao novo Pegem - Manufatura Limpa.

\begin{tabular}{|c|c|c|}
\hline Período & PEGEM & Conceito \\
\hline $\begin{array}{l}\text { Antes do } \\
\text { século XX }\end{array}$ & $\begin{array}{c}\text { Manufatura } \\
\text { artesanal }\end{array}$ & $\begin{array}{l}\text { Womack et.al (1992) relata que eram caracterizadas por força de trabalho altamente qualificada em projeto, produção e } \\
\text { montagem, empresas descentralizadas com volume de produções baixíssimos. }\end{array}$ \\
\hline $\begin{array}{c}\text { Início do } \\
\text { século do } \\
\text { XX } \\
\end{array}$ & $\begin{array}{c}\text { Manufatura } \\
\text { em Massa }\end{array}$ & $\begin{array}{l}\text { Godinho (2004) revela que nesse período havia alta divisão do trabalho, alto grau de repetitividade, com produção } \\
\text { baseada no baixo custo, explorando economias de escala. }\end{array}$ \\
\hline $\begin{array}{l}\text { Década de } \\
1950 \text { a } 1970\end{array}$ & $\begin{array}{l}\text { Manufatura } \\
\text { Enxuta }\end{array}$ & $\begin{array}{l}\text { Godinho (2004) diz que a ênfase passou a ser na melhoria das operações, eliminação de desperdícios e retrabalhos, } \\
\text { diminuição do set up das máquinas com o intuito de redução do tamanho dom lote de produção e consequentemente } \\
\text { aumento na variedade de produtos oferecidos aos clientes. Em } 1960 \text { ocorreu um grande crescimento na participação no } \\
\text { mercado automotivo devido "à alta qualidade e baixos custos" (BUFFA, 1984). Em } 1970 \text { as empresas passam a focar } \\
\text { em produzir sem defeitos, com inovações nos processos e pontualidade de entrega. }\end{array}$ \\
\hline $\begin{array}{l}\text { Surgiu em } \\
1987\end{array}$ & $\begin{array}{l}\text { Manufatura } \\
\text { Responsiva }\end{array}$ & $\begin{array}{l}\text { Booth (1996) relata que esta nova estratégia da gestão da manufatura enfatiza a redução do tempo de desenvolvimento } \\
\text { de produto e do tempo de produção como fatores vitais para o aumento da competitividade de uma empresa. }\end{array}$ \\
\hline $\begin{array}{l}\text { Surgiu em } \\
1987\end{array}$ & $\begin{array}{c}\text { Customização } \\
\text { em Massa }\end{array}$ & $\begin{array}{l}\text { Da Silveira et al (2001) define como a habilidade de fornecer produtos e serviços projetados individualmente para cada } \\
\text { consumidor através de altíssima agilidade, flexibilidade no processo, integração e custo baixo. }\end{array}$ \\
\hline $\begin{array}{l}\text { Surgiu em } \\
1991\end{array}$ & $\begin{array}{l}\text { Manufatura } \\
\text { Ágil }\end{array}$ & $\begin{array}{l}\text { Sharifi \& Zhang, (1999); De Vor et. al. (1997) entende como objetivo responder às mudanças inesperadas de maneiras } \\
\text { correta e no tempo devido e saber explorar estas mudanças. }\end{array}$ \\
\hline $\begin{array}{l}\text { De } 2000 \text { até } \\
\text { atual }\end{array}$ & $\begin{array}{l}\text { Manufatura } \\
\text { Limpa }\end{array}$ & $\begin{array}{l}\text { Os autores puderam constatar recentemente a preocupação com a redução da poluição e também melhorias na vantagem } \\
\text { competitiva em empresas que processam produtos e serviços com responsabilidade socioambiental. Com certeza esse } \\
\text { paradigma está afetando as formas de organizar o trabalho, principalmente pela necessidade de implementar a P+L e } \\
\text { Ecologia Industrial focadas na Sustentabilidade. O objetivo principal é de conscientização e educação ambiental dos } \\
\text { envolvidos e conquistar da certificação ISO } 14000 \text {. Por um lado, a organização favorece a redução da poluição, } \\
\text { apresentando vantagens ambientais; por outro, ganham em competitividade e vantagens econômicas. }\end{array}$ \\
\hline
\end{tabular}

Quadro 2 - Evolução dos Pegem (elaborado pelos autores). 


\section{Modelo de PPCPEA}

Por meio de uma intensiva pesquisa bibliográfica, não foi observada na literatura a preocupação ambiental para a tomada de decisão no planejamento e controle da produção. Vários autores relatam apenas sobre os aspectos de prazos do sistema produtivo e mencionam cada tipo de sistema ou processo adequado para que o planejamento se torne realidade. Mas na nova forma de estruturar a produção, é necessário que o PPCP se complemente com a educação ambiental (Figura 2), porque é possível reduzir energia, água e matéria-prima que se verão refletidas em benefícios ambientais e econômicos.

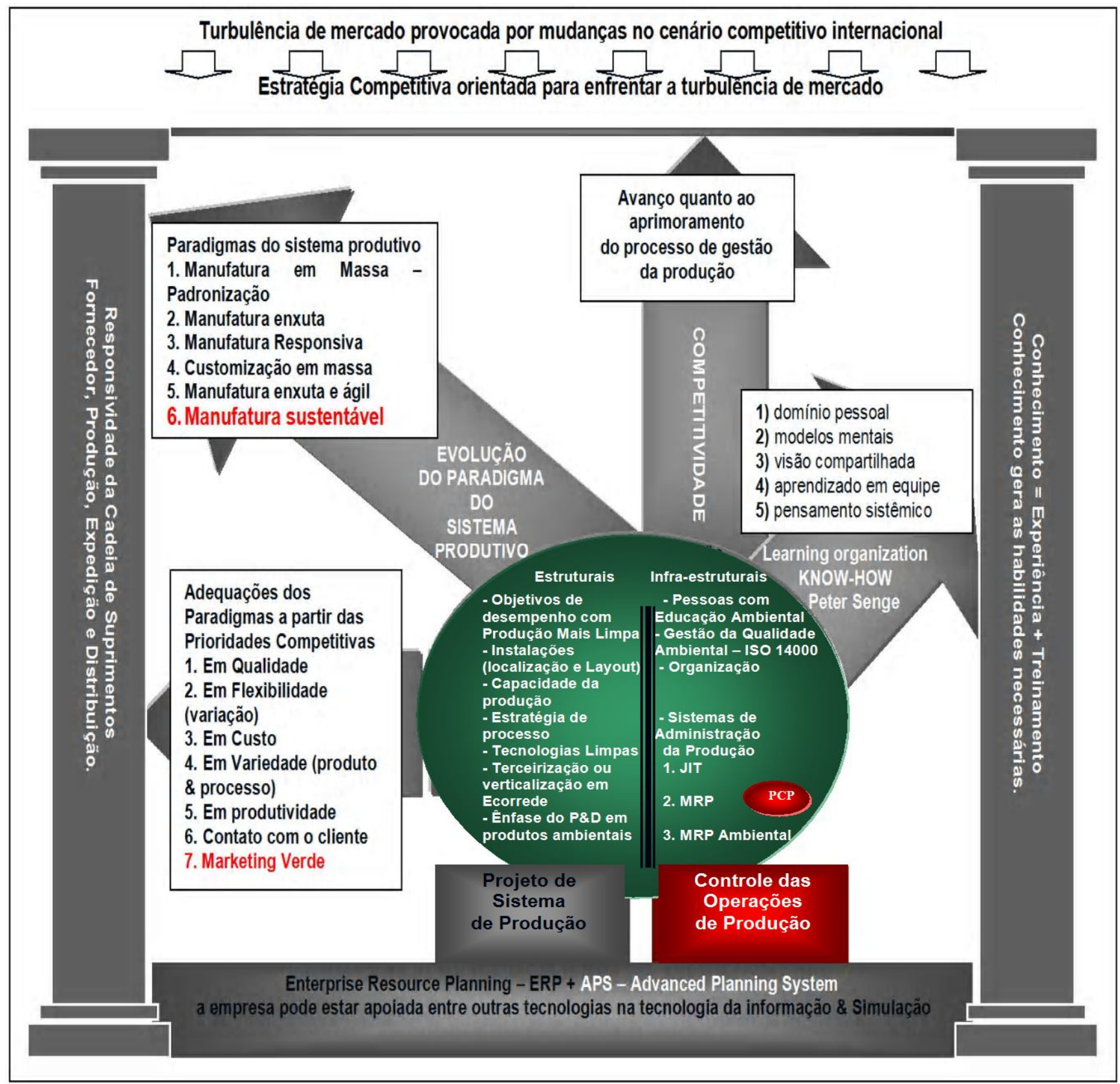

Figura 2 - Implementação do novo PEGEM no sistema produtivo.

Fonte: Azzolini Jr. (2004), adaptado pelos autores. 


\section{Conclusões}

A necessidade de adequar-se a partir de um processo de sistematização dos procedimentos inerentes ao PPCP induz as empresas de diversos segmentos a buscar soluções de tecnologia da informação e gerenciamento dos sistemas de produção adequados à nova conjuntura mundial de competitividade.

O profissional que atua no PPCP precisa implementar $\mathrm{P}+\mathrm{L}$ no sistema produtivo evoluindo para um PPCPEA, considerando as instalações, a capacidade, a tecnologia e a verticalização ou terceirização, a fim de reduzir a poluição e adquirir vantagens econômicas. $\mathrm{O}$ conceito de "fazer mais com menos" de Womack (1992) corrobora coma definição de ecoeficiência, segundo Giannetti e Almeida (2006), no qual a empresa pode, por meio da $\mathrm{P}+\mathrm{L}$, adquirir vantagens econômicas e ambientais. Sendo assim, percebe-se uma estreita ligação com a Manufatura Enxuta.

Para a implementação estrutural do PPCPEA, é imprescindível planejar a infraestrutura. Os aspectos considerados importantes iniciam-se coma necessidade de instruir e disseminar conceitos sobre educação ambiental internamente, tanto quanto de conscientizar e criar Eco Times; segundo, implementar na gestão da qualidade a política ambiental acompanhada da certificação ISO 14000; terceiro, estabelecer no plano estratégico da empresa a estreita relação entre PPCP enxuto e a $\mathrm{P}+\mathrm{L}$ com o objetivo de implementar a nova concepção de PPCPEA no sistema de produção; e, quarto, disseminar conscientização ambiental na empresa, a fim de envolver a estrutura, objetivando a aceitação à evolução paradigmática do sistema produtivo para uma manufatura limpa. Para isso, é de extrema importância a simplificação dos fluxos produtivos, e a necessidade de se adaptar à $(\mathrm{P}+\mathrm{L})$ mostram outros aspectos envolvidos na complexidade do novo modelo.

Para a nova estruturação da produção é necessário que se adicione um objetivo de desempenho relativo à sustentabilidade ambiental. As instalações precisam se adequar em termos de layout e processo. Faz-se necessária a implementação de tecnologias limpas na manufatura, assim como de fechar ciclos por meio de estruturação de ecorredes, a fim de disseminar educação ambiental para os fornecedores, agentes terceirizados e clientes. O planejamento do produto final com a adoção de eco-design completa os aspectos plausíveis de serem modificados e que foram analisados em termos de estrutura.

\section{REFERÊNCIAS}

ALLEN, T.F.H; TAINTER, J.A.; HOEKSTRA, T.W. Supply-side sustainability. Systems Research and Behavioral Science, v.16, p.403427, 1999.

AMAZONAS, Maurício de Carvalho. Desenvolvimento sustentávele teoria econômica: o debate conceitual nas perspectivas neoclássicas, instituicuinalista e da economia ecológica" In: NOBRE, Marcos \& Maurício Amazonas (Orgs.)

Desenvolvimento Sustentável. A institucionalização de um conceito. Brasilia:Ibama, , 2002.

ANDRADE, R.O.B; TACHIZAWA, T; CARVALHO, A.B; Gestão Ambiental - enfoque estratégico Aplicado ao Desenvolvimento Sustentável, São Paulo: Makron Books, 2000.

ASIAN PRODUCTIVITY ORGANIZATION, Greening Supply Chain: Enhancing Competitiveness through Green Productivity. Asian Productivity Organization, 2001.

AZZOLINI JR, W. Tendências do processo de evolução do sistema de administração da produção. Dissertação ( Doutorado em Engenharia de Produção) - Universidade Federal de São Carlos- USP, 2004.

BARBIERI, J.C ; CAJAZEIRA, J.E.R. Responsabilidade social empresarial e empresa sustentável: da teoria à prática. São Paulo: Saraiva, 2009. 
BARBIERI, J.C. Gestão ambiental empresarial: conceitos, modelos e instrumentos. 2.ed. São Paulo: Saraiva, 2007.

BOOTH, R; Agile Manufacturing. Engineering Management Journal, v. 6, n.2, April de 1996.

BOWEN, F.; COUSINS, P.; LAMMING, R.; FARUK, A. The role of supply management capabilities in green supply", Production an Operations Management, v. 10, n. 2, p. 174-89, 2001.

BUFA, E.S; Meeting the competitive Challenge, Irwin, 1984.

CARVALHO, M.M.; PALADINI, E.P.; Gestão da Qualidade - Teorias e casos. Rio de Janeiro: Elsevier, 2005.

\section{CERTO, Samuel C. PETER, J.P. Administração} estratégica: planejamento e implantação da estratégia. São Paulo: Pearson Education do Brasil, 2005.

CONTADOR, J.C.; Campos e armas da competição: novo modelo de estratégia, São Paulo: Saint Paul Editora, 2008.

CORRÊA, H.L; GIANESI, I.G.N; CAON M. Planejamento, Programação e Controle da Produção: MRP II/ERP: conceitos, usos e implementação: base para o SAP, Oracle Applications e outros softwares integrados de gestão. 5 ed. São Paulo: Atlas, 2007.

DA SILVEIRA, G; BORENSTAIN, D; FOGLIATTO, F.S. Mass Customization: literature review and research directions. Internation Journal of Productions Economics. v. 72, 2001.

DE VOR, R.; GRAVES, R.; MILLS J.J. Agile manufacturing research: accomplishments and opportunities. IIE Transation, vol. 29, 1997.

DICONÁRIO HOUAISS DA LÍNGUA PORTUGUESA. Significado da Palavra:

"Terceirização". [on-line] Disponível em:www. URL:http://houaiss.uol.com.br/ busca.jhtm?verbete=terceirização\&stipe $=\mathrm{k}$. Arquivo Acesso em: 20 março 2008.

FURTADO, J.S. Sustentabilidade Empresarial. Guia de práticas econômicas, ambientais e sociais, Salvador, 2005.

GAITHER, N.; FRAZIER, G. Administração da Produção e operações. 8.ed., São Paulo: Thomson Learning, 2002.

GIANNETTI, B. F.; ALMEIDA, C. M. V. B. Ecologia industrial: conceitos, ferramentas e aplicações. São Paulo: Edgard Blucher, p.3-18, 2006.

GIL, A. Como elaborar projetos de pesquisa.

4.ed.. São Paulo: Atlas, 2002.

GODINHO FILHO, M.; Paradigmas

Estratégicos de Gestão da Manufatura: configurações, relações com o planejamento e controle da produção e estudo exploratório na indústria de calçados. Dissertação (Doutorado em Engenharia de Produção) - Universidade Federal de São Carlos: São Carlos, 2004.

HALL, J. Environmental supply chain dynamics. Journal of clean production, v. 8, n. 3, p. 455471, 2000.

INTITUTE OF OCEANOGRAPHY. Nível de $\mathrm{CO}^{2}$ na atmosfera. Disponível em: http:// www.nio.org. Acesso em: 20 dezembro 2009.

KRAJEWSKI, L.J. Administração de produção e operações. São Paulo: Pearson Prentice Hall, p. $258-294,2009$. 
KUHN, T.S.; A estrutura das relações científicas. São Paulo: Editora Perspectiva, 1962.

LEWIS, Michael et al. Operations management: critical perspectives on business and management. Routledge: New York, 2003.

NBR ISO 14001:2000; Associação Brasileira de Normas Técnicas. Rio de Janeiro: ABNT: 2003.

NEVENS, F., DESSEIN, J., MEUL, M., ROGGE, E., VERBRUGGEN, I., MULIER, A., PASSEL, S.V., LEPOUTRE,J., HONGENAERT, M. 'On tomorrow's grounds', Flemish agriculture in 2030: a case of participatory translation of sustainability principles into a vision for the future. Journal of Clean Production. n. 16, p.10621070, 2008.

NIELSEN, S.N.; MULLER, F. Understanding the functional principles of nature-proposing another type of ecosystem services. Ecological Modelling, p.1913-1925, 2009.

NORMAN, E. D. Distribution requeriments planning: problems and promises. Cleveland, Ohio: Patrick Gallagther. Proceedings of the Logístics Resources, Fórum, 1983.

OLIVEIRA NETO, G.C. Integração complexa entre empresa contratante e operador logístico: critérios para a contratação. Dissertação (Mestrado em Engenharia de Produção) - Instituto de Ciências Exatas e Tecnológicas, Universidade Paulista, 2008.

ROTONDARO, R.G., Gerenciamento por Processos. In:: OLIVEIRA, O.J., Gestão da qualidade: tópicos avançados. São Paulo: Thomson, 2004.

SACOMANO,J.B.: Decisões no Planejamento e Controle da Produção: In COSTA NETO, Pedro
Luiz de Oliveira, Qualidade e competência nas decisões. São Paulo: Blücher, 2007.

SARKIS, J., A strategic decision framework for Green supply chain management. Journal of clean Production, v.11, n.4, p.. 397-409, 2003.

SENAI.RS. Implementação de Programas de Produção mais Limpa. Porto Alegre: Centro Nacional de Tecnologias Limpas SENA-RS/ UNIDO/INEP, 2003.

SHARIFI, H. \& ZHANG, Z.: A methodology for achieving agility in manufacturing in the UK industry. International Journal of Production Economics, v. 62, 1999.

SHIN, D., CURTIS.,M., HUISING.,D., ZWETSLOOT, G.I. Development of a sustainability polity model for promoting cleaner production: a knowledge integration approach. Journal of Clean Production, n. 16, p.1823-1837, 2008.

SLACK, NIGEL.; CHAMBERS, STUART,; JOHNSTON, ROBERT.; Administração da Produção. 2. ed. São Paulo: Atlas, , 2007.

SUNKEL, Osvaldo.; A sustentabilidade do desenvolvimento atual In: ARBIX, Glauco, Mauro Zilbovicius \& Ricardo Abramovay (orgs). Razões e ficcões do desenvolvimento: São Paulo: Editora UNESP \& EDUSP, 2001.

TACHIZAWA, T. e ANDRADE, R.O.B; Gestão Socioambiental: estratégia na nova era da sustentabilidade. Rio de Janeiro: Elsevier, 2008.

TAINTER, J.A, ALLEN, T.F.H., LITTLE, A., HOEKSTRA, T.W. Resource transitions and energy gain: contexts of organization. Conservation Ecology, 2003.

TAYLOR, D. A. Logística na cadeia de 
Suprimentos: uma perspectiva gerencial. São Paulo: Pearson Addison-Wesley, 2005.

THRANE, M., NIELSEN, E.H., CHRISTENSEN, P. Clean Production in Danish fish processing experiences, status and possible future strategies. Journal of Clean Production, v. 17, p. 380-390, 2009.

TSOULFAS, G.T., PAPPIS, C.P., A model for supply chains environmental performance analysis and decision making. Journal of Clean Production, v. 16, p. 1647-1657, 2008.

TUBINO, D.F. Planejamento e Controle da Produção: teoria e prática. São Paulo: Atlas, 2007

\section{US EPA, The Lean and Green Supply Chain:}

A practical Guide for Materials Managers and Supply Chain Managers to Reduce Costs and Improve Environmental Performance, US: EPA, 2000.

VAIS, A., MIRON, V., PEDERSEN, M., FOLKE, J.; Lean and Green at a Romanian secondary tissue paper and board mill - putting theory into practice, Resources Conservations \& Recycling, 2006.

VAN HOCK, R. I.; ERASMUS, I. From reversed logists to green supply chains. Logists solutions Issue, v.2, p. 28-33, 2000.
VEIGA, José Eli da.; Desenvolvimento Sustentável: o desafio do século XXI": Rio de Janeiro: Garamond, 2005.

WALTON, S., HANDFIELD,R., MELNYK, S., The green supply chain: integrating suppliers into environmental management processes.

International Journal of Purchasing and Materials Management, Spring, 1998.

WOMACK, J. P., JONES. D.T. A mentalidade enxuta nas empresas: elimine o desperdício e crie riqueza. Rio de Janeiro: Elsevier, 2004.

WOMACK, J. P., JONES. D.T., ROOS, D. A máquina que mudou o mundo. Rio de Janeiro: Campus, p.1-39, 1992.

WRIGHT, Peter, PARNELL, John. Administração Estratégica: conceitos. 4. ${ }^{\mathrm{a}}$ ed. São Paulo: Atlas, 2000.

YUKSEL, H., Na empirical evaluation of clean production pratices in turkey. Journal of Clean Production 16S1.p. 50-57, 2007.

ZHU, Q., SARKIS, J., CORDEIRO, J.J., LAI, K.H., Firm-level correlates green supply chain management pratices in the Chinese context. Omega the international Journal of Management Science. n. 36, p. 577-591, 2008. 